\title{
Impacts of extreme air temperatures on cyanobacteria in five deep peri-Alpine lakes
}

\author{
Nicole GALLINA*, Orlane ANNEVILLE ${ }^{1)}$ and Martin BENISTON \\ Climate Change and Climate Impacts Research Group, Institute for Environmental Sciences (ISE), University of Geneva, \\ 7 rte de Drize, $\mathrm{CH}-1227$ Carouge, Switzerland \\ ${ }^{1)}$ INRA, UMR CARRTEL, Stn Hydrobiol. Lacustre, 75 Ave Corzent, F-4203 Thonon Les Bains, France \\ *e-mail corresponding author: nicole.gallina@unige.ch
}

\begin{abstract}
Cyanobacteria are of major interest in freshwater ecosystems, since they are able to produce toxins with potentially negative impacts on the environment, health and thus on economics and society. It is therefore important for water management authorities to assess the manner in which cyanobacteria may evolve under climate change, especially in the Alpine Region where warming is projected by climate models to be more important than the global average. In this study, air temperature extremes under current climate were used as a proxy for future "average" climate forced by enhanced greenhouse gas concentrations. The impacts of extreme temperature events on cyanobacteria were analyzed in five deep peri-Alpine lakes, covering the entire trophic gradient and using a synoptic approach. Extreme air temperatures were observed to alter the biomass of the cyanobacteria community. In general, extreme hot events are associated with high biomass while extreme cold events are characterised by low biomass. However, the assessed air temperature extremes did not lead to a dominance of cyanobacteria over the other phytoplankton groups, which also showed responses in relative biomass change during extreme events. Both extreme hot and extreme cold events were seen to generate a loss of diversity among cyanobacteria. In addition, the use of extreme events as a proxy to "average" future climates is a useful approach to enhance possible impacts of future global warming on the biota in freshwater systems. The outcomes of a synoptic approach provide general responses and are a useful tool for further modelling purposes.
\end{abstract}

Key words: climate change, biodiversity, phytoplankton, meteorological forcing, synoptic study

\section{INTRODUCTION}

Under current warming trends at the global and regional scales, extreme events such as heat waves are becoming more frequent (IPCC 2007). The summer of 2003 was probably the hottest summer in Europe in the past 500 years, where locally temperatures were $5{ }^{\circ} \mathrm{C}$ above the long-term summer average (Beniston 2004; Luterbacher et al. 2004). For future climate, climate models suggest that one summer in two may be at least as hot as the 2003 event (Beniston 2007) by the end of the $21^{\text {st }}$ Century. In other words, what is today considered a hot extreme event could become the norm in a "greenhouse climate" by 2100 . The use of current data on extremes as a form of proxy for the future thus enables an assessment of the possible impacts on the natural environment (Beniston 2007).

Cyanobacteria, which are a pigmentary group of phytoplankton, can be found in all aquatic ecosystems, ranging from hydrothermal springs to Arctic zones. Cyanobacteria are of importance since they are the major phytoplankton group in freshwater ecosystems capable of producing toxic blooms (Carmichael et al. 1990). Such toxins can become a major problem for public health if contaminated water is stored in reservoirs, and used in irrigation, fishing, cultivation and rec- reational purpose (Codd 1995; Chorus 2001; Codd et al. 2005).

As the Earth's oldest known oxygen-producing organism (Schopf 2000), cyanobacteria have played a key role in evolution since their first appearance 2.15 billion years ago (Hoffmann 1975; Knopf 2006; Ramussen 2008). The long life history of cyanobacteria is responsible of their capacity to be well adapted to environmental stress including scarce and abundant nutrients (Paerl 2006), exposure to UV, high solar radiation and above all high temperatures (Paerl et al. 1985; Robarts \& Zohary 1987; Briand 2004). These particular environmental conditions may favour the dominance of cyanobacteria in many aquatic habitats. The specific ability of cyanobacteria to be very tolerant when subjected to various stress factors suggest that cyanobacteria are likely to benefit from environmental changes associated with global warming (Paerl \& Huisman 2008; Paerl 2009).

These finding also lead to questions related to the capacity of cyanobacteria to become dominant under future climate regimes. It seems that under warming in shallow non-stratified lakes, the phytoplankton community is not changed and its diversity is maintained (Moss et al. 2003) whereas Elliot et al. (2006) suggest that the potential of cyanobacteria to dominate the community is 


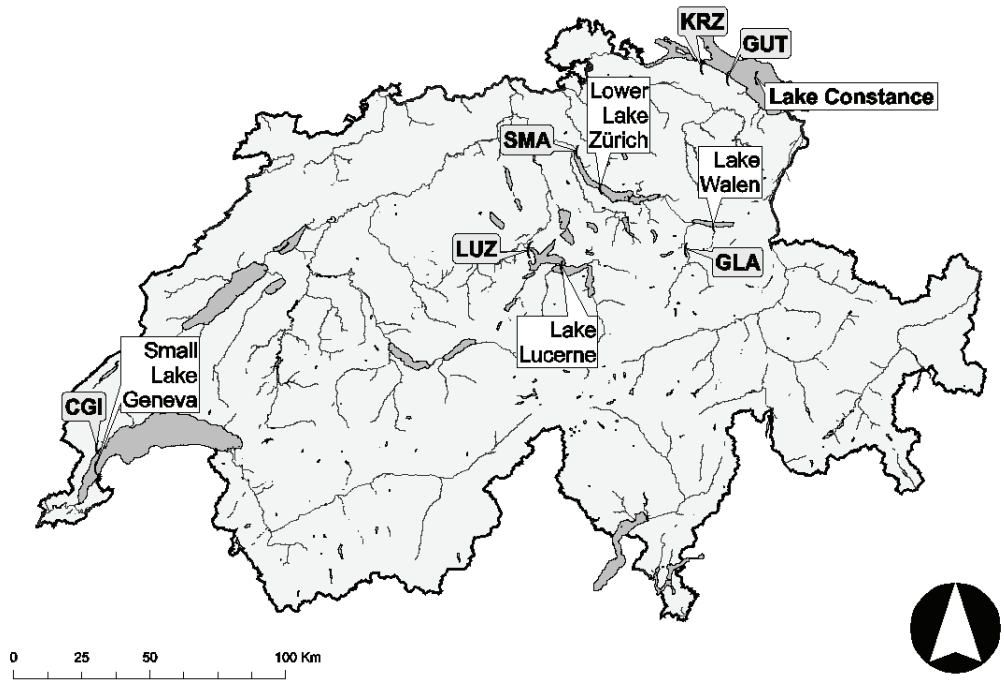

Fig. 1. Map of Switzerland indicating the lakes and the meteorological stations referred to in the text. See tables 1 and 2 for the names and characteristics of the selected lakes.

greatest with higher water temperatures combined with more elevated nutrient loads.

It has been hypothesised that the proliferation of cyanobacteria may be more important under the warmer climatic conditions projected for the coming decades of the $21^{\text {st }}$ Century. A further paradigm is that the impact of warming may lead to an alteration of the phytoplankton development (Paul 2008; Paerl \& Huisman 2009), and therefore to a possible change in the community structure.

Warming patterns directly influence air temperature, which in turn represents an indirect link between atmospheric conditions and aquatic ecology. Shifts in air temperatures are probably the first step in a causal chain of processes, which leads to hydrological and ecological changes in lakes (Straile 2000), as for example warmer water temperatures (George \& Hewitt 1999; Staile 2000), a more stable water column, a stronger and longer-lasting stratification with probable impacts on the availability of nutrients in the epilimnion (Perroud et al. 2009) as well as in the hypolimnon (Søndergaard et al. 2003). Mean lake temperatures have been increasing in responses to warmer weather. However, precise predictions of all possible responses of lake temperatures are difficult because of the complex interaction between aquatic environments and the atmosphere. Data indicate that in some cases, there may also have been direct responses of ecosystem functions to a warming climate (De Stasio et al. 2009). The model results of Perroud \& Goyette (2010) on the prediction of the water temperature profiles of Lake Geneva indicate that there will be a rising of epilimnic temperatures corresponding to 55$98 \%$ of the monthly increase in air temperature under the IPPC $2 \mathrm{~A}$ scenario.

It is well known that multitude of factors affecting the growth of cyanobacteria that exhibit a complex and synergistic relation to each other (Dokulil \& Teubner
2000). An important driver for phytoplankton growth is nutrient load, that itself can be partly driven by changes in inflow related to runoff in rivers upstream of the lakes. While changes of nutrient loads are not the main focus of the present paper, this topic will be briefly addressed at the discussion part.

Because of the numerous impacts that warmer air temperatures is capable of exerting on physical, chemical and biological factors in lake ecosystems, the aim of this study is firstly to assess whether extreme air temperatures recorded during past years have been able to affect the biomass of cyanobacteria. If this is the case, the second goal consists to analyse, if the changes in the cyanobacteria biomass has the potential to influence the diversity of the phytoplankton community.

The principle idea was not only to have the response of cyanobacteria in one lake, but to analyse their response in several lakes, in order to obtain a broader picture of what is taking place. In order to achieve this intention, data from five lakes was used; they are all deep lakes located within the peri-Alpine Region. The five lakes have different trophic status and cover the entire trophic gradient from eutrophic to oligotrophic.

\section{MATERIALS AND METHODS}

\subsection{Locations and data description}

For this study, phytoplankton data from five, deep peri-Alpine lakes were analysed (Lake Constance, Lake Zurich, Lake Walen, Lake Lucerne and Lake Geneva). Lake Lucerne was split into two different data sets, as the sampling point for Lake Lucerne changed from Kreuztrichter (used until 1997) to Obermatt (since 1998).

The geographic locations of these lakes are shown in figure 1. Table 1 summarises the hydro-morphological characteristics, the trophic level as well as the time 
Tab. 1. List of lakes studied in the present paper, summarized by their time period, trohphic levels and hydromorphological caracteristics.

\begin{tabular}{ccccccccc}
\hline Lake Name & Time Period & Trophic state & $\begin{array}{c}\text { Altitude } \\
(\mathrm{m})\end{array}$ & $\begin{array}{c}\text { Surface } \\
\left(\mathrm{km}^{2}\right)\end{array}$ & $\begin{array}{c}\text { Mean Depht Max. Depht } \\
(\mathrm{m})\end{array}$ & $\begin{array}{c}\text { Volume } \\
(\mathrm{m})\end{array}$ & $\begin{array}{c}\text { Retention Time } \\
(\mathrm{y})\end{array}$ \\
\hline Constance & $1985-1990$ & Eutroph & 395 & 472 & 101 & 252 & 48 & 4.3 \\
Lower Zurich & $1981-1990$ & Meso-Eutroph & 406 & 65 & 51 & 136 & 3.3 & 1.4 \\
Walen & $1991-2000$ & Oligotroph & 420 & 24 & 100 & 145 & 2.42 & 1.4 \\
Lucerne Kreuztrichter & $1987-1996$ & Oligo-Mesotroph & 434 & 113 & 104 & 214 & 11.8 & 3.4 \\
Lucerne Obermatt & $1998-2004$ & Oligo-Mesotroph & 434 & 113 & 104 & 214 & 11.8 & 3.4 \\
Small Geneva & $2001-2005$ & Oligo-Mesotroph & 372 & 81 & 41 & 76 & 3 & 0.4 \\
\hline
\end{tabular}

Tab. 2. Summary of the phytoplankton survey in the different lakes.

\begin{tabular}{|c|c|c|c|}
\hline Lake Name & Institution & Sampling point & Sampling Depth \\
\hline Constance & $\begin{array}{l}\text { LUBW (Landesanstalt für Umwelt, Messungen und } \\
\text { Naturschutz Baden- Wurtenberg; Institut für } \\
\text { Seenforschung; Langenargen }\end{array}$ & FU (Fischbach-Uttwil) & $0-20 \mathrm{~m}$ \\
\hline Lower Zürich & Wasserversorgung Zürich & TH (Thalwil) & $\begin{array}{c}0 \mathrm{~m}, 1 \mathrm{~m}, 2.5 \mathrm{~m}, 5 \mathrm{~m}, 7.5 \mathrm{~m} \\
10 \mathrm{~m}, 12.5 \mathrm{~m}, 15 \mathrm{~m}, 20 \mathrm{~m}\end{array}$ \\
\hline Walen & Wasserversorgung Zürich & MU (Murg) & $\begin{array}{c}0 \mathrm{~m}, 1 \mathrm{~m}, 2.5 \mathrm{~m}, 5 \mathrm{~m}, 7.5 \mathrm{~m} \\
10 \mathrm{~m}, 12.5 \mathrm{~m}, 15 \mathrm{~m}, 20 \mathrm{~m}\end{array}$ \\
\hline Lucerne & $\begin{array}{c}\text { EAWAG (Swiss Federal Institute of Aquatic Science and } \\
\text { Technology ) }\end{array}$ & $\begin{array}{l}\text { KZ (Kreuztrichter), OB } \\
\text { (Obermatt) }\end{array}$ & $0-20 \mathrm{~m}$ \\
\hline Small Geneva & $\begin{array}{l}\text { SECOE (Service Cantonal de I'Ecologie de l'Eau); } \\
\text { Geneva }\end{array}$ & GE 3 & $0-20 \mathrm{~m}$ \\
\hline
\end{tabular}

period used for each lake. All the water bodies sampled in this study are deep, monomictic lakes and belong to the same geographical (peri-Alpine) and climatological (continental) region. These common characteristics enable all lakes to be studied together. The trophic state of each lake was derived from the classification of the total phosphorus concentration according to the Organisation for Economic Cooperation and Development (OECD 1982). Oligotrophic lakes have a total phosphorus concentration lower than $10 \mathrm{mg} \mathrm{m}^{-3}$, mesotrophic lakes are classified as having a total phosphorus concentration in between $10-35 \mathrm{mg} \mathrm{m}^{-3}$ and if the lakes reach a total phosphorus concentration in the range 35$100 \mathrm{mg} \mathrm{m}^{-3}$, they are considered eutrophic. The lakes cover the entire trophic gradient, which provides an opportunity to assess the overall phytoplankton response (Winder \& Schindler 2004) to the impact of extreme air temperature in this particular region, whatever the trophic state of the lake. The conclusions drawn for deep lakes may not necessarily hold for shallow lakes, however.

\subsection{Phytoplankton data}

Monthly or bi-monthly phytoplankton sampling data were obtained from state water authorities responsible for lake monitoring and from limnological research institutes. Table 2 gives an overview of the survey methods and sampling points applied during the different monitoring programs. All institutes employed the same counting method designed by Utermöhl (1958).

Due to the fact that the species nomenclature changed during the periods under consideration, species identification followed the more recent monographs of the series "Süsswasserflora von Mitteleuropa" established by A. Pascher (Gustav Fischer Verlag, and Elsevier, Spectrum Akademischer Verlag) as well as "The freshwater algal flora of the British Isles" (John et al. 2002). To further reduce the counting biases between different institutions, the species biomass was added to the genera biomass, which was finally expressed in $\mu \mathrm{g}$ $\mathrm{L}^{-1}$. For further statistical analyses, we attempt to distinguish between the well-known genera able of producing toxins and the genera for which there have been very sporadic or no records of toxicity up till now. We divided the cyanobacteria genera in two categories: the first includes the total cyanobacteria biomass and the second the potentially-toxic cyanobacteria biomass. This allowed to study separately the cyanobacteria biomass responsible for generating potentially critical situations for water management. The key genera known for their potential ability to produce toxic substances include Anabaena, Aphanizomenon, Coelosphaerium, Oscillatoria, Plankthothrix, Pseudoanabaena, Synechococcus, Woronichinia (Carmichael 2001). The Cyanobacteria genera presented in the lakes investigated here and not known to produce any toxins are: Aphanocapsa, Aphanothece, Chroococcus, Cyanobacterium, Cyanothece, Dactylococcopsis, Gleitlerinema, Gomphosphaeria, Jaaginema, Leptolyngbya, Limnothrix, Lyngbya, Merismopedia, Pannus, Phormidium, Planktolyngbya, Pleurocapsa, Rhabdogloea, Snowella, Spirulina, Synechocystis.

The uppermost water layers from 0-20 m were taken into account in the present study. Data from discrete 
depths have been transformed into weighted averages integrated over the water column from 0-20 m depth.

\subsection{Meteorological data}

The daily average air temperature data were downloaded from the digital database of the Swiss Federal Office for Meteorology and Climatology (MeteoSwiss). Five meteorological stations have been chosen (Fig. 1), based upon their proximity to the phytoplankton sampling points, namely Güttingen (GUT) and Kreuzlingen (KRZ) for Lake Constance; Zürich/Fluntern (SMA) for lower Lake Zürich; Glarus (GLA), for Lake Walen; Lucerne (LUZ) for Lake Lucerne and Changins for the the narrow western segment of Lake Geneva (Small Lake Geneva or Petit Lac). The dataset has been quality-checked for homogeneity in the records (Bergert et al. 2005). Cross-correlation analyses based on phytoplankton distribution showed that the best responses to meteorological data were obtained when taking the temperature values on the fifth day before the sampling day. Therefore, air temperatures five days prior to plankton sampling were used, in order to respect the response time of phytoplankton to meteorological events.

\subsection{Statistical Methods}

Extreme air temperature (hereafter referred to as ET) enabled the derivation of a number of sample classes (ET-Classes). Each phytoplankton sampling date was recorded into 3 different classes, each of which was defined with the help of percentiles. For each lake, the monthly $1^{\text {st }}$ percentile and the $99^{\text {th }}$ percentile of air temperature were computed for the common reference period from 1961-1990. If the corresponding air temperature of the sampling date was between the $1^{\text {st }}$ and the $99^{\text {th }}$ percentile of the reference period, the sampling date was classified into the "normal" or "non-extreme" class. For the case where the air temperature was below the $1^{\text {st }}$ percentile of the reference period, the sampling date was classified as an extreme cold sample; conversely, extreme hot samples were dates for which the air temperature exceeded the $99^{\text {th }}$ percentile. For the total of 705 samples among the lakes, we classified 419 events into "normal" events, 193 samples into "extreme hot" events and 93 samples into "extreme cold" events.

Use of the percentiles rather than the two original sets of data provide a measure of objective interpretation of what may constitute a cold or a warm extreme, that can be transposed from one lake to another even if the true temperature values may be different for these selected thresholds.

Due to a sparsity of data for Lake Constance, two meteorological stations were taken into account to compute the reference period. From 1961 to 1975 the air temperature was downloaded from the station of Kreuzlingen (KRZ) and from 1976 to 1990 from Güttingen (GUT) (Fig. 1).
In order to assess the impact of extremes on the seasonal cyanobacteria biomassand its diversity, the average of the sampling months corresponding to the same seasons was calculated, within the lakes and affiliated to the same ET-Class. The cyanobacteria biomass for each ET-Class and each season was derived, thus representing a form of "virtual, season" in peri-Alpine lakes. The winter season included samples from December, January and February; spring was defined from March to May, summer from June to August and autumn from September to November.

\subsection{Model}

A linear mixed-effect model was used to test the influence of temperature and the significance of the different ET-Classes on cyanobacteria biomass and on phytoplankton community diversity. For this purpose we employed the lmer function from the lme4 package (Bates \& Maechler 2009) in the R software (R Development Core Team, 2009). The lme4 Model is very robust when using S4 classes (Chambers 1998). The S4 class is an object oriented programming originally used by the S-Language and adopted by the $\mathrm{R}$ software. Contrary to the old S3 class system, the S4 object system is much richer, thus allowing an easier implementation of functions and is robust enough to support real software engineering. Applying S4 objects, classes and methods become much more formal and rigorous. The lme4 Model is based on the restricted maximum likelihood estimation method and able to handle unbalanced data. ET-Classes were defined as model predictors, while the total cyanobacteria biomass, the potentially toxic cyanobacteria biomass as well as diversity were defined as the response variables. As each lake has its specific effect on the phytoplankton growth as does water chemistry and environmental factors (Reynold \& Walsby 1975; Lung \& Perl 1988; Ryding \& Rast 1989; Blenckner 2005), the lake identity was set as random effect, assigned as "lake effect", which allows the model to take into account the variability that can exist between the different lakes.

The significance ( $p$-value) of the fixed effects was tested with the Markov Chain Monte Carlo (MCMC) method on 10,000 permutations.

\subsection{Biodiversity}

The goal of using biodiversity was to assess possible changes in the phytoplankton community as a result of impacts related to extreme air temperatures. As the outcomes of several studies indicate changes of biodiversity in lakes (Magnusson 1997; Sala et al. 2010), this raises the question of whether the phytoplankton community analysed in the sampled lakes result in a loss or in a gain in biodiversity, as there are opposite number of counteracting effects that can occur (Heino 2009). Indeed, a dominance of cyanobacteria may well occur as a result of climate change (Elliot 2006; Wagner \& Adrian 
2009), but it is still unclear whether these changes may lead to a loss (Elliot 2006) or to a gain in diversity of the phytoplankton community (Magnuson 1997). As different groups are likely to respond differently to temperature change (Moss 2003), we calculated the genera diversity $(\mathrm{H})$ among phytoplankton groups, using the Shannon-Weaver function (Shannon \& Weaver 1949) implemented in the "vegan" package (Oksanen 2009) available from the R Software (R Development Core Team 2009):

$$
H^{\prime \prime}=-\sum\left(b_{i} / B\right) \log _{2}\left(b_{i} / B\right)
$$

where $B$ is the total biomass of each phytoplankton group, $b_{i}$ is the biomass of the ith genera present. The diversity index was applied to the main phytoplankton groups present in the studied lakes, which included in addition to Cyanobacteria, Chlorophyceae, Diatoms, Dinophyceae, Chrysophyceae, Conjugatophyceae and Cryptophyceae.

The monthly biomass average was thus derived for each lake and each phytoplankton group. The effect of each ET-Class, as well as its significance, to phytoplankton group diversity was calculated in using the lmer function implemented in the lme4 Model. The lake identity was used as random effect. ET-Classes were defined as predictors and biodiversity as the response variable.

\section{RESULTS}

\subsection{Effects of extreme air temperatures on the total and on the potentially toxic cyanobacteria biomass}

Each ET-Class has a highly significantly effect on total and potentially toxic cyanobacteria (Tab. 3). Warm temperatures have a positive effect, inducing an increase in biomass while cold temperatures lead to a decrease. The impact of these effects on cyanobacteria biomass can be visualised with the help of the bar graphs in figure 2. Bar graphs highlight the mean and the standard error of all samples belonging to the same ET-Class. It appears that hot events are characterised by significantly higher cyanobacteria biomass, while cold events are characterized by lower biomass. Graphs A and B in figure 2 show an increase of the same order of magnitude for both total and potentially toxic cyanobacteria in relation to air temperatures.

Tab. 3. Significance of the different ET-Classes (Hot, Cold, Normal) to the total and the potentially-toxic cyanobacteria biomass, evaluated by the "lme4" Model. The significance of the model was tested with help of the MCMC method ( $p$ value). All ET-Classes are significant for values of $p<0.05$.

\begin{tabular}{|c|c|c|c|c|}
\hline & \multicolumn{2}{|c|}{$\begin{array}{l}\text { Total cyanobacterial } \\
\text { biomass }\left(\mu \mathrm{g} \mathrm{L}^{-1}\right)\end{array}$} & \multicolumn{2}{|c|}{$\begin{array}{c}\text { Total potentially toxic } \\
\text { cyanobac. biomass }\left(\mu \mathrm{g} \mathrm{L}^{-1}\right)\end{array}$} \\
\hline & Estimates & $p$-value & Estimates & $p$-value \\
\hline Hot & 3.055 & 0.001 & 2.497 & 0.001 \\
\hline Cold & -0.961 & 0 & -0.794 & 0 \\
\hline Normal & -0.447 & 0.006 & 0.332 & 0.001 \\
\hline
\end{tabular}

A

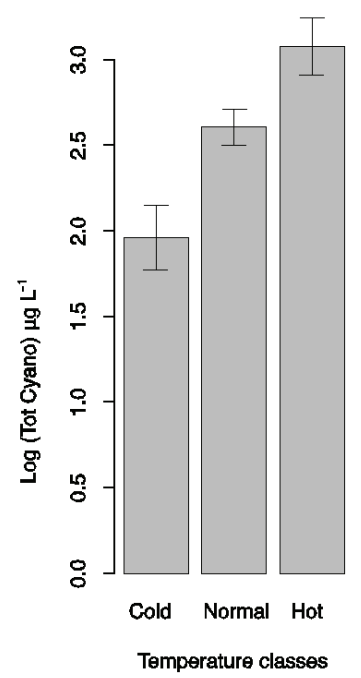

B

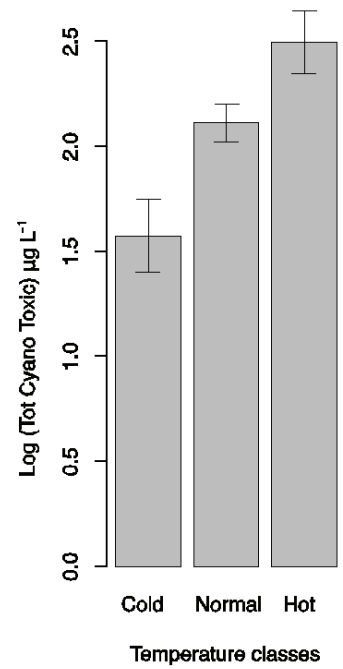

Fig. 2. Mean and standard error for each ET-Class derived from A) the log-transformed total cyanobacteria biomass [Log (TotCyano)] and B) the log-transformed total toxic cyanobacteria biomass [Log (TotCyanoToxic)].

\subsection{Distributions of temperature inducing a change in the development of cyanobacteria}

The box plot graphical method was used to display the distribution of air temperature measured during the periods of phytoplankton sampling, grouped by class and seasons. The aim was to define the range of recorded air temperatures that are capable of inducing an increase in cyanobacteria biomass. For this reason, we focused on measurements for which we identified a high rate of proliferation of cyanobacteria during extreme events, as was the case for hot extremes in general, and more specifically during hot summers and autumns, as well as for cold winters. We compared these temperature spreads with air temperatures recorded during normal events (Fig. 3).

During extreme hot events, the recorded air temperature had a median value of $14.8{ }^{\circ} \mathrm{C}$, and $50 \%$ of the values were distributed between $9.1{ }^{\circ} \mathrm{C}$ and $19{ }^{\circ} \mathrm{C}$. On the other hand, samples within the normal classes exhibited an air temperature distribution with a median value of $9.9^{\circ} \mathrm{C}$ and an inter-quartile range between $3.3{ }^{\circ} \mathrm{C}$ to $15.9^{\circ} \mathrm{C}$.

In summer, the median air temperature for normal events and extreme hot events was $17.4{ }^{\circ} \mathrm{C}$ and $21.3{ }^{\circ} \mathrm{C}$, respectively. Under normal condition, the $25^{\text {th }}$ percentile was $16.3{ }^{\circ} \mathrm{C}$ and the $75^{\text {th }}$ percentile was $18.6{ }^{\circ} \mathrm{C}$, while under extreme hot summer conditions, these percentiles increased to $20.1{ }^{\circ} \mathrm{C}$ and $22.5^{\circ} \mathrm{C}$, respectively.

In autumn, temperatures tend to be more variable than in summer, such that the inter-quartile range under normal conditions was between $6.9^{\circ} \mathrm{C}$ and $14^{\circ} \mathrm{C}$, and the median air temperature was $10.9{ }^{\circ} \mathrm{C}$. Hot extremes ranged from $9.6^{\circ} \mathrm{C}$ to $17.4{ }^{\circ} \mathrm{C}$, with a median value of $12.7^{\circ} \mathrm{C}$. 

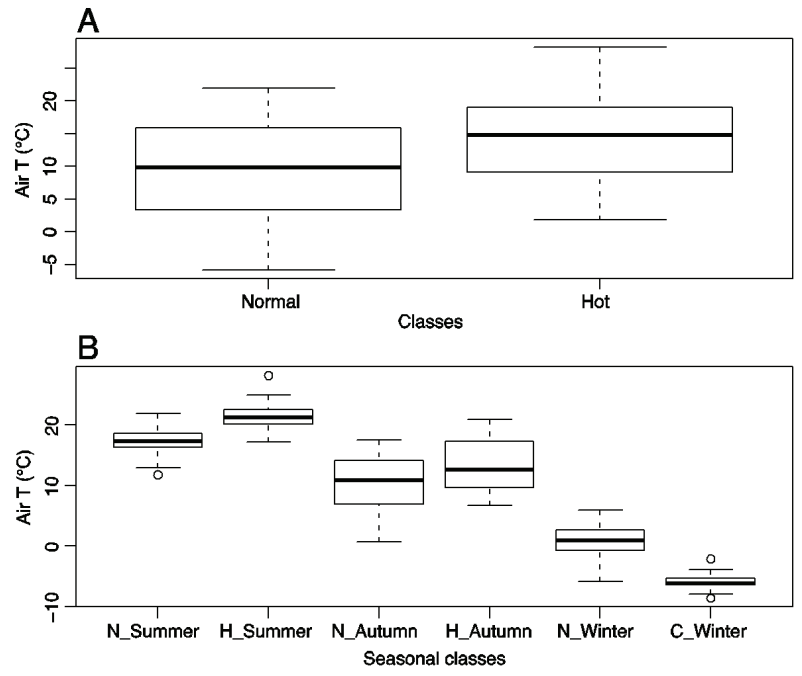

Fig. 3. A) Box-plot graphics displaying the median (thick line), the upper $\left(75^{\text {th }}\right.$ percentile $)$ and lower $\left(25^{\text {th }}\right.$ percentile $)$ quartiles, the minimum and maximum values from Normal (N) and Hot (H) ET-Classes. B) The seasonal air temperature distribution of Hot and Normal ET-classes for summer and autumn are also shown, as well as for Normal and Cold (C) winters.

Strong cyanobacteria proliferation has also been observed even during cold winter extremes. The air temperature has a median value of $-6.1^{\circ} \mathrm{C}$, with a small inter-quartile range between $-6.4{ }^{\circ} \mathrm{C}$ and $-5.3{ }^{\circ} \mathrm{C}$. Normal air temperatures in winter, on the other hand, exhibit a median value of $1{ }^{\circ} \mathrm{C}$, where $50 \%$ of the values were distributed between $-0.7^{\circ} \mathrm{C}$ and $2.7^{\circ} \mathrm{C}$.

\subsection{Consequence of cyanobacteria biomass increase on the phytoplankton community}

The relative seasonal biomass of ET-Classes was analysed taking into consideration the major phytoplankton groups. The aim of assessing the relative cyanobacteria biomass was to emphasize whether the cyanobacteria, which under normal conditions exhibit a low relative biomass contribution, have the potential to become dominant under extreme events (Fig. 4). Even though their biomass has been observed to increase under such events, cyanobacteria do not appear to dominate the other phytoplankton groups during extreme hot (mainly summer and autumn) and extreme cold (mainly winter) events. Moreover, it seems that the relative proportion of biomass between the different ETClasses and within the same season remains similar. Nevertheless, the graphical presentation of figure 4 indicates that the different algal groups change their relative biomass in different manners according to the assessed ET-classes and seasons.

\subsection{Effects of extreme air temperature on phytoplankton community diversity}

Biodiversity changes among phytoplankton groups for the different ET-classes were investigated, with a special focus on cyanobacteria. Table 4 summarises the results obtained by means of the lmer method. Surprisingly, air temperature affected every phytoplankton group under extreme cold events. Air temperature was also able to significantly influence the biodiversity of all phytoplankton groups under normal conditions. This

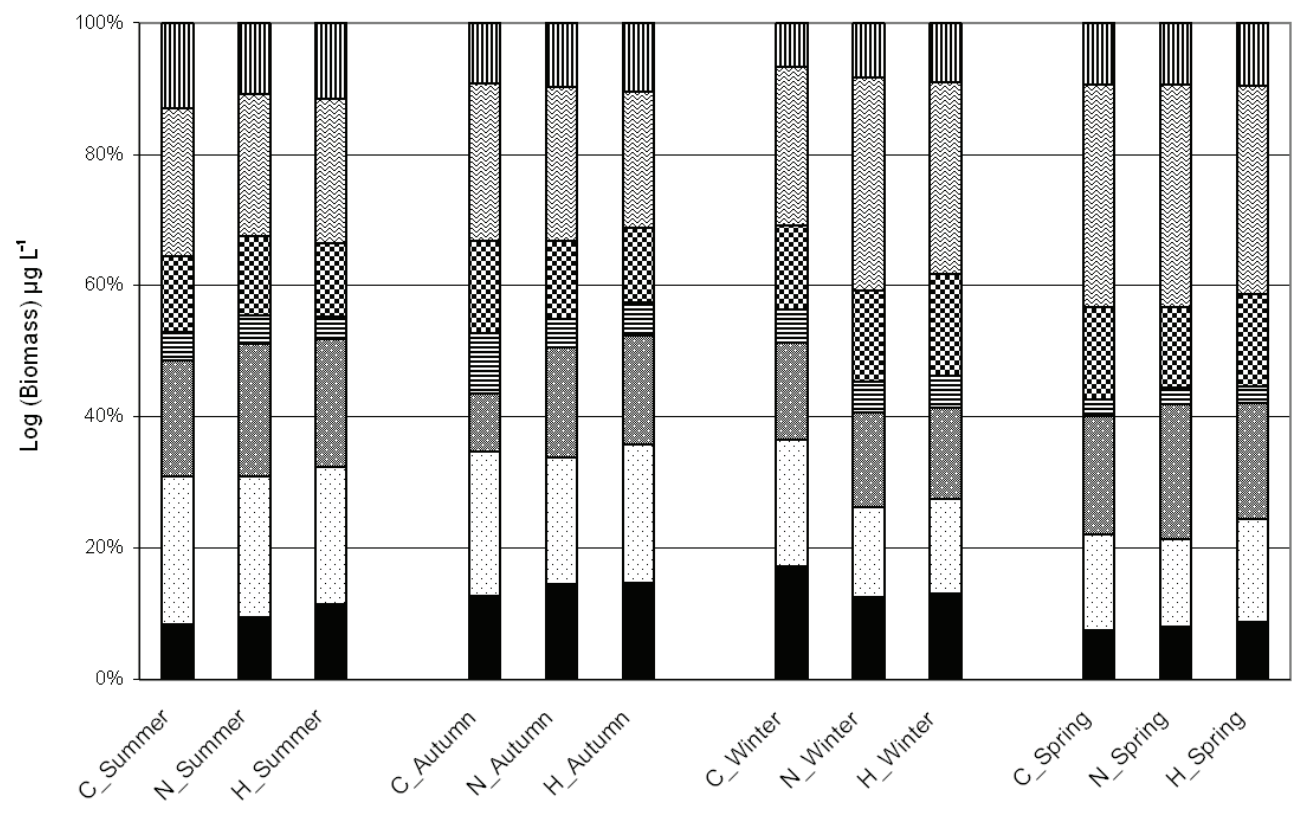

Cyanobacteria $\square$ Chlorophyceae $\square$ Chrysophyceae 目Conjugatophyceae $\mathbf{0}$ Cryptophyceae 圈 Diatoms 血Dinophyceae

Fig. 4. Relative seasonal biomass of the major phytoplankton groups for each ET-Class $(C=C o l d ; N=N o r m a l, H=H o t)$. 
Tab. 4. Significance of the effect of ET-Class to biodiversity of the major phytoplankton groups evaluated by the "lme4" Model and tested with the MCMC method ( $p$-value). The effects are significant for $p<0.05$ and are highlighted in bold.

\begin{tabular}{|c|c|c|c|c|c|c|}
\hline & \multicolumn{2}{|c|}{ Cold } & \multicolumn{2}{|c|}{ Normal } & \multicolumn{2}{|c|}{ Hot } \\
\hline & $\begin{array}{c}\text { Estimates } \\
\left(\mu \mathrm{g} \mathrm{L}^{-1}\right)\end{array}$ & $p$-value & $\begin{array}{c}\text { Estimates } \\
\left(\mu \mathrm{g} \mathrm{L}^{-1}\right)\end{array}$ & $p$-value & $\begin{array}{c}\text { Estimates } \\
\left(\mu \mathrm{g} \mathrm{L}^{-1}\right)\end{array}$ & $p$-value \\
\hline Cyanobacteria & 3.323 & $\mathbf{0}$ & 1.347 & $\mathbf{0}$ & 0.809 & 0.016 \\
\hline Chlorophyceae & 7.452 & $\mathbf{0}$ & 3.269 & $\mathbf{0}$ & 1.475 & 0.089 \\
\hline Cryptophyceae & 2.446 & $\mathbf{0}$ & 0.209 & 0.005 & 0.127 & 0.075 \\
\hline Dinophyceae & 4.223 & $\mathbf{0}$ & 1.31 & $\mathbf{0}$ & 0.519 & 0.09 \\
\hline Diatoms & 6.666 & $\mathbf{0}$ & 1.412 & $\mathbf{0}$ & 0.345 & 0.29 \\
\hline Chrysophyceae & 5.427 & $\mathbf{0}$ & 1.707 & $\mathbf{0}$ & 0.563 & 0.152 \\
\hline Conjugatophyceae & 2.252 & $\mathbf{0}$ & 0.262 & 0.09 & 0.278 & 0.083 \\
\hline
\end{tabular}
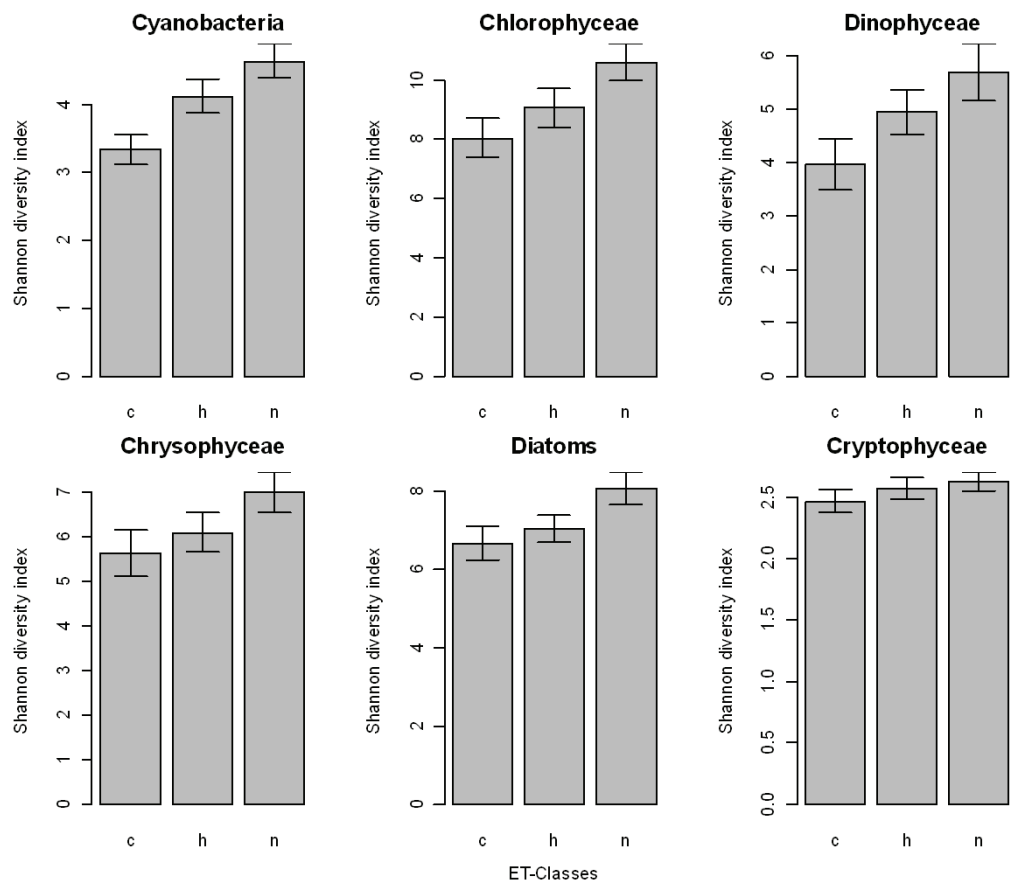

Fig. 5. Average and standard error of the biodiversity of the major phytoplankton groups derived for each ET-Class $(\mathrm{c}=\mathrm{Cold}$; $\mathrm{h}=$ Hot, $\mathrm{n}=$ Normal).

outcome indicates that biodiversity is statistically different, and significantly so, under normal conditions compared to cold extreme events, for all phytoplankton groups with the exception of Conjugatophyceae. However, an unexpected result of this study is that there is a significant loss in biodiversity only for cyanobacteria during extreme hot events. In order to measure the biodiversity change for every phytoplankton group among ET-classes, we used the bar graph method derived from the average of the Shannon-Weaver Index for each class among each phytoplankton group (Fig. 5). The Conjugatophyceae were not taken into account, because of the general lack of significant changes during normal as well as extreme hot temperature conditions. An overall loss of biodiversity in the phytoplankton community is seen to take place whenever extreme cold events occur compared to normal events. Caution is necessary, however, in the interpretation of the biodiversity effect within the warm ET-Class, because of the low $p$-values among the different phytoplankton groups. Nevertheless, if air temperature rises, biodiversity tends to be lower than under normal conditions.

The cyanobacteria community showed on the other hand a significant loss of biodiversity for both of the extreme cases considered. Cyanobacteria seem to be the most vulnerable to changes in temperature. Figure 6 shows the same effects in summer, autumn and winter, where a loss of diversity occurs during extreme warm as well as during extreme cold events. Under the latter conditions, biodiversity decreased more than under the former one. In spring, the seasonal pattern is the reverse of the other seasons; cyanobacteria gain in biodiversity, for both extreme hot and cold spring events.

\section{DISCUSSION}

The purpose of this study was to use extreme air temperatures as observed in recent years as a proxy for a warmer climate that is projected to occur over the next 


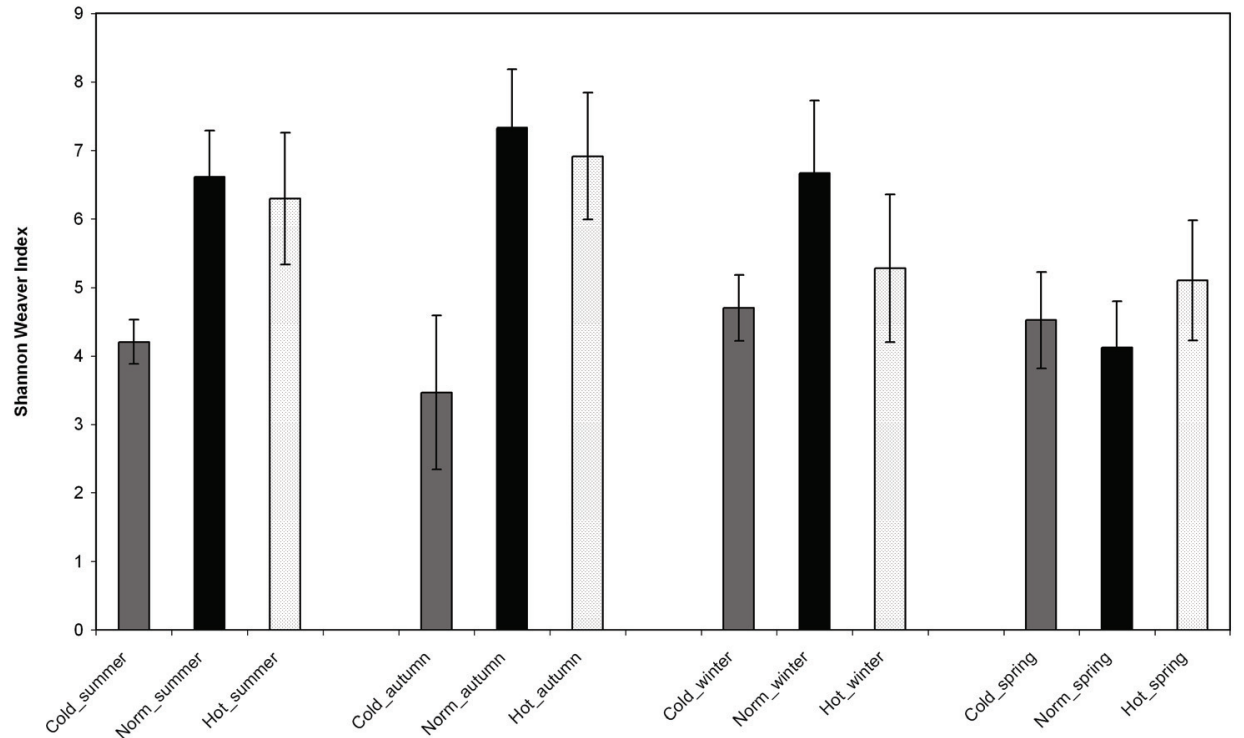

Fig. 6. Yearly and seasonal averages of the cyanobacteria diversity derived from monthly values represented by the different ETClasses. The bars represent the standard deviations.

50-100 years (e.g., Beniston et al. 2007; IPCC 2007), in order to assess the response of cyanobacteria biomass and diversity in deep continental lakes.

The altered response of the cyanobacteria community to the different ET-Classes suggests that air temperature has an impact on cyanobacteria biomass in deep peri-Alpine lakes. Potential toxic cyanobacteria and non toxic cyanobacteria genera seem to respond in the same way and magnitude to air temperature extremes. Given the time lag of 5 days used in this study, which is considered to be the response time of phytoplankton to meteorological changes, it is suggested here that air temperature is able to affect phytoplankton biomass in a rather rapid way. The use of air temperature as a proxy for water temperature, in the uppermost meters of the lake waters and during summer, was also discussed by Livingstone (1998). Based on these findings, air temperature can be considered as a reliable indicator of biotic processes, such as cyanobacteria behaviour within the epilimnion. Similar results were found for Microcystis, in a eutrophic lake during the summer heatwave of 2003 , by means of a lake experiment and with the help of a biological-physical model (Jöhnk et al. 2008). The conclusions of that work suggest that air temperature directly affects cyanobacteria through an increased growth rate, and indirectly via the stabilisation of the water column favouring buoyant cyanobacteria over other non-buoyant phytoplankton groups. Other similar results were found in a sub-Alpine lake in northern California through a long-term study by Park et al. (2004), which showed that cyanobacteria biomass increases during warmer years. Furthermore, it was concluded that higher water temperatures were accompanied by increasing cyanobacteria biomass in summer. De Senerpont et al. (2007) observed through experiments with mesocosms and mechanistic models that the growth rates as well the abundance of cyanobacteria were higher during warm springs than cold ones, particularly in lakes whose conditions were phosphorus-limited.

Nevertheless, the relative proportion of the different phytoplankton groups during extreme events is, unexpectedly, well maintained. It seems that a constant composition governs phytoplankton groups, which is not able to be disturbed by the extreme events recorded. Neither cyanobacteria nor any other phytoplankton group became dominant under extreme events. The overall phytoplankton development over the season and among phytoplankton groups was well maintained. Furthermore, atmospheric warming does not appear to affect any particular pattern in taxonomy (Moss et al. 2003). These findings suggest that the constant composition under both types of extreme events seems to be well maintained. This may be due to the fact the different genera respond in different ways to shifts in temperature (Heino 2009; Moss et al. 2003). These altered responses are, however, not strong enough to disturb the phytoplankton composition. Using the findings by Elliot et al. (2006) on cyanobacteria dominance, it is suggested that for the present study, summer and autumn heat-waves probably did not reach critical thresholds beyond which a collapse of the constant composition that would favour the dominance of cyanobacteria over other species would be observed. Under extreme hot seasons, compared to normal season, median air temperature increased in autumn by 4 ${ }^{\circ} \mathrm{C}$, by $2.9^{\circ} \mathrm{C}$ in summer, and decreased by $5.1{ }^{\circ} \mathrm{C}$ in winter. These air temperature differences are able to 
trigger an increase in cyanobacteria biomass; however, temperature changes alone are not sufficient to induce the domination of cyanobacteria. It can be hypothesised, however, that once these thresholds are exceeded, a possible community functional change is likely to take place.

Biodiversity among the different phytoplankton groups is surprisingly affected more by cold extreme events than by warm ones. All of the major phytoplankton groups respond significantly to these cold extremes. A decrease in biodiversity can be expected under extreme cold events for all phytoplankton groups. Hot extreme events, in contrast, influence only cyanobacteria in a significant way. This emphasizes the point that cyanobacteria are perhaps the most sensitive phytoplankton group when it comes to biodiversity under hot temperature regimes. Although the shifts in the biodiversity of the other major phytoplankton groups under hot events are low, a decrease in phytoplankton biodiversity may occur under such conditions. These finding confirm Elliot's et al. (2006) results, derived for only eight dominant species belonging to different phytoplankton groups. With higher air temperatures, cyanobacteria biomass increases, but its diversity decreases. This suggests that fewer genera lead to higher biomass, which is only possible if one or several genera begin to proliferate excessively. Similar results were obtained by Duarte et al. (2006), who studied the relationship between ecosystem functioning and structure in coastal lagoons, suggesting a decrease in diversity is associated with an increase in biomass and production. However, the impact of extreme warm air temperatures to overall phytoplankton community structure could not be ascertained from this study. This is because of the lack of a significant response of the major phytoplankton groups to heat waves, with the exception of cyanobacteria. Further work will be necessary to assess the questions related to the interaction between community structure and function.

It should be stressed that nutrient loads are also a major driving force, in addition to water temperatures (Moss et al. 2003; Elliot et al. 2006; Stich \& Brinker 2010). In a future climate, however, warmer summer temperatures will not have the same impacts on discharge as they do under current climate, because up to $90 \%$ of current Alpine glacier mass may be lost by 2100 , according to future levels of greenhouse-gas emissions. With such reductions, and the projected seasonal shifts in precipitation towards much drier summers (e.g., Beniston 2006), many rivers originating in the Alps may see sharp decreases in runoff compared to current climate (e.g., Beniston 2010). Nutrient availability will clearly be influenced by these longterm, sustained changes in river discharge, thus requiring further investigations to include the influence of nutrient availability in addition to that of temperature discussed in the present paper.
It is important to reveal that each lake is reflects its particular environment, which is defined in Bleckner's (2005) conceptual model of climate-related effects on lake ecosystems as the "Internal Lake Filter". It is, however, interesting to emphasize that the conclusions for different lakes under different trophic statuses, based on the different methods outlined in the literature, from insitu studies, mesocosms experiments, and model simulations, all point to the similar response of cyanobacteria biomass increase with higher air and water temperatures. This common conclusion confirms the validity of the use of the synoptic approach applied in this study.

Finally, this study shows that the use of extreme events is a reasonable proxy to assess future climate change, particularly in cases where time series are not available. As these extreme events are likely to become more common, it can be expected that the potentially toxic as well as the total cyanobacteria biomass should also increase with a corresponding loss in biodiversity. Such a conclusion should help to develop possible adaptation strategies that could help reduce some of the associated risks of climatic change (Beniston 2007), in particular on water quality and human health.

\section{CONCLUSIONS}

Extreme air temperatures are a useful proxy to investigate cyanobacteria development in deep periAlpine lakes in a changing climate, and could be applied as possible indicator of changes in biological processes in the upper layers of the water column. Extreme warm events favour a development of cyanobacteria biomass, whereas cold extreme temperatures tend to induce a decrease in biomass. No differences between the responses of potential toxic and non toxic cyanobacteria biomass to air temperature could be observed. However, even under conditions of increasing biomass during extreme conditions, cyanobacteria were not able to dominate the phytoplankton community. Surprisingly, extreme cold events also had a significant impact on the major phytoplankton groups investigated, resulting in an overall community diversity loss. Hot extreme events had a significant impact only on cyanobacteria. A loss of diversity could be expected for the cyanobacteria community under both extreme hot and extreme cold events. As more frequent extreme events are expected in a warmer global climate, an enhanced biomass increase and diversity loss among the cyanobacteria community can be anticipated. This study concludes that synoptic in situ approaches are appropriate tools for a general assessment of the impacts of meteorological forcing on similar lakes located in the same geographical and/or climatological region and provide necessary information for further investigations.

It will be necessarily to improve the understanding of the strength of meteorological effects on phytoplankton behaviour, compared to the internal physicochemical and biological influences, such as grazing 
pressure and competition. This understanding is of primary importance when it comes to model cyanobacteria development under scenarios of global warming.

\section{ACKNOWLEDGEMENTS}

The authors wish to thank N. Salmaso for his useful advice and S. Lavigne for helping us with the identification of the phytoplankton species. Special thanks go to the different institutes providing the phytoplankton data, namely: Dr. R. Kümmerlin from the LUBW, Dr. R. Forster from the Wasserversorung Zürich, Dr. H. R. Bürgi from the EAWAG Dübendorf, Dr. J. Perfetta from the SECOE from Geneva, as well as the CIPEL. In addition, the authors extend their thanks to the Swiss Office for Meteorology and Climatology (MeteoSwiss) for allowing the use of their meteorological data. This work was supported by the University of Geneva and contributes indirectly to the research objectives of the EU/FP7 "ACQWA" project (www.acqwa.ch) funded by the European Union under Grant Nr. 212250.

\section{REFERENCES}

Bates, D. \& M. Maechler. 2009. lme4: Linear mixed-effects models using S4 classes. R package version 0.999375-31. http://CRAN.R-project.org/package=lme4.

Begert, M., T. Schlegel. \& W. Kirchhofer. 2005. Homogenous temperature and precipitation series of Switzerland from 1864 to 2000. International Journal of Climatology, 25: 65-80.

Beniston, M. 2004. The 2003 heat wave in Europe: a shape of things to come? An analysis based on Swiss climatological data and model simulations. Geophysical Research Letters, 31, L02202, doi: 10.1029/2003 GL018857.

Beniston, M. 2006. The August 2005 intense rainfall event in Switzerland: not necessarily an analog for strong convective events in a greenhouse climate. Geophysical Research Letters, 33, L5701

Beniston, M. 2007. Entering into the "greenhouse century": recent record temperatures in Switzerland are comparable to the upper temperature quantiles in a greenhouse climate. Geophysical Research Letters, 34, L16710.

Beniston, M. 2010. Impacts of climatic change on water and associated economic activities in the Swiss Alps. $J$. Hydrol., doi:10.1016/j.jhydrol.2010.06.046.

Beniston, M., D.B. Stephenson, O.B. Christensen, C.A.T. Ferro, C. Frei, S. Goyette, K. Halsnaes, T. Holt, K. Jylhä, B. Koffi, J. Palutikoff, R. Schöll, T. Semmler \& K. Woth. 2007. Future extreme events in European climate; an exploration of Regional Climate Model projections. Climatic Change, 81: 71-95.

Blenckner, T. 2005. A conceptual model of climate-related effects on lake ecosystems. Hydrobiologia, 533: 1-14.

Briand, J.F., C. Leboulanger \& J.F. Humbert. 2004. Cylindrospermopsis raciborskii (cyanobacteria) invasion at mid-latitudes: selection, wide physiological tolerance, or global warming. J. Phycol., 40: 231-238.

Carmichael, W.W. 2001. A mini-review of cyanotoxins; toxins of cyanobacteria (blue-greenalgae). In: W.J. de Koe, R.A Samson, H.P. van Egmond, J. Gilbert, M. Sabino \& W.J. de Koe (Eds), Microcystin and phycotoxins in perspective and the turn of the millennium. Ponson \& Looyen, Wageningen, The Netherlands: 495-504.

Carmichael, W.W., N.A. Mahmood \& E.G. Hyde. 1990. Natural toxins from cyanobacteria (blue-green algae). In: S. Hall \& G. Strichartz (Eds), Marine toxins: origin, struc- ture, and molecular pharmacology. American Chemical Society, Washington, DC: 87-106.

Chambers, J.M. 1998. Programming with Data - A Guide to the S Language. Springer-Verlag: $469 \mathrm{pp}$.

Chorus, I. 2001. Cyanotoxins: Occurrence, Causes, Consequences. Berlin: Springer-Verlag: 375 pp.

Codd, G.A. 1995. Cyanobacterial toxins: Occurrence, properties and biological significance. Water Science and Technology, 32: 149-156.

Codd, G.A., L.F. Morrison \& J.F. Metcalf. 2005. Cyanobacterial toxins: risk management for health protection. Toxicology and applied Pharmacology, 203: 264-272.

De Stastio, B.T., T. Golemgeski \& D.M. Livingstone. 2009. Temperature as a driving factor in aquatic ecosystems. Encyclopedia of Inland Waters. Elsevier Inc.: 690-698.

De Senerpont Domis, L.N., W.M. Mooij \& J. Huisman. 2007. Climate-induced shifts in an experimental phytoplankton community: a mechanistic approach. Hydrobiologia, 584: 403-413.

Duarte, P., M.F. Macedo \& L. Cancela de Fonseca. 2006. The relationship between phytoplankton diversity and community function in coastal lagoon. Hydrobiologia, 555: 3-18.

Elliot, J.A., I.D. Jones \& S.J. Thackeray. 2006. Testing the sensitivity of phytoplankton communities to changes in water temperature on nutrient load, in a temperate lake. Hydrobiologia, 559: 401-411.

George, D.G. \& D.P. Hewitt. 1999. The influence of year-toyear variations in winter weather on the dynamic of Daphnia and Eudiaptomus in Estwaite Water, Cumbria. Functional Ecology, 13: 45-54.

Heino, J., R. Virkkala \& H. Toivonen. 2009. Climate change and freshwater biodiversity: detected patterns, future trends and adaption in northern regions. Biol. Rev., 94: 39-54.

Hofmann, H.J. 1976. Precambrian microflora, Belcher Islands, Canada: Significance and systematics. J. Paleontol., 50: 1040-1073.

IPCC. 2007. Climate Change 2007: Synthesis Report. Contribution of Working Groups I, II and III to the Fourth Assessment. Report of the Intergovernmental Panel on Climate Change [Core Writing Team, Pachauri, R.K and Reisinger, A.(Eds)]. IPCC, Geneva, Switzerland: 104 pp.

John, D.M., A.J. Brooks \& B.A. Whitton. 2002. The freshwater algal flora of the British Isles. An identification guide to freshwater and terrestrial algae. Cambridge University Press: $702 \mathrm{pp}$.

Jöhnk, K.D., J. Huisman, J. Sharples, B. Sommeijer, P.M. Visser \& J.M. Stroom. 2008. Summer heatwave promote bloom of harmful Cyanobacteria. Global change biology, 14: 495-512.

Knopf, A. H., E. J. Javaux, D. Hewitt \& P. Cohen. 2006. Eukaryotic organisms in Proterozoic oceans. Philosophical Transactions of the Royal Society B, 361: 1023-1038.

Livingstone, D.M. \& A.F. Lotter. 1998. The relationship between air and water temperatures in lakes of the Swiss Plateau: a case study with palaeolimnological implications. J. Paleolimnol., 19: 181-198.

Lung, W.S. \& H.W. Pearl. 1988. Modelling green-blue algal blooms in the Lower Neuse River. Wat. Res., 22: 895-905.

Luterbacher, J., D. Dietrich, E. Xoplaky, M. Grossjean \& H. Wanner. 2004. European seasonal and annual temperature variability, trends, and extremes since 1500. Science, 303: $1499-1503$.

Magnuson, J.J., K.E. Webster, R.A. Assel, C.J. Bowser, P.J. Dillon, J.G. Eaton, H.E. Evans, D.J. Fee, R.I. Hall, L.R. Mortsch, D.W. Schindler \& F.H. Quinn. 1997. Potential effects of climate change on aquatic systems: Laurentian Great Lakes and Precambrian Shield Region. In: C.E. Cushing (Ed.), Freshwater ecosystems and climate change in North America: a regional assessment. Advances in Hydrological Processes. John Wiley\& Sons: 7-53. 
Moss, B., D. McKee, D. Atkinson, S.E. Collings, J.W. Eaton, A.B. Gill, I. Harvey, K. Hatton, T. Heyes \& D. Wilson. 2003. How important is climate? Effects of warming, nutrient addition and fish on phytoplankton in shallow lake microcosms. Journal of applied Ecology, 40: 782-792.

OECD. 1982. Eutrophicaton of waters. Monitoring, assessment and control. Organisation for Economic Cooperation and Development: $193 \mathrm{pp}$.

OFEV. 2009. Hydrological data online at URL: http://www. hydrodaten.admin.ch/f/index.htm?lang=fr

Oksanen, J., R. Kindt, P. Legendre, B. O'Hara, G.L. Simpson, P. Solymos, M.H. Stevens \& H. Wagner. 2009. Vegan: Community Ecology Package. R package version 1.15-3. http://CRAN.R-project.org/package=vegan.

Paerl, H.W. 2008. Nutrient and other environmental controls of harmful cyanobacteria blooms along the freshwater-marine continuum. Advances in Experimental Medicine and Biology, 619: 216-241.

Paerl, H.W. \& J. Huisman. 2008. Blooms like it hot. Science, 320: $57-58$.

Paerl, H.W. \& J. Huisman. 2009. Climate change: a catalyst for global expansion of harmful algal blooms. Environmental Microbilogy Reports, 1(1): 27-37.

Paerl, H.W., P.T. Bland, N.D. Bowles \& M.E. Haibach. 1985. Adaptation to high intensity, low wavelength light among surface blooms of the cyanobacterium Microcystis aeruginosa. Appl. Environ. Microbiol., 49: 1046-1052.

Park, S., M.T. Brett, A. Müller-Sorger, C.R. Goldmann. 2004. Climatic forcing and primary productivity in a subalpine lake: Interannual variability as a natural experiment. Limnol. Oceanogr., 49: 614-619.

Paul, V.J. 2008. Global warming and cyanobacterial harmful algal booms. In: K.H. Hudnell (Ed.), Cyanobacterial harmful algal blooms: state of the science research needs series. Springer Adv. Exp. Med. Biol., 619: 239-257.

Perroud, M. \& S. Goyette. (2011). Impacts of a warmer climate on Lake Geneva water temperature profiles. Boreal Environment Research: (Submitted)

R Development Core Team. 2009. R: A Language and Environment for Statistical Computing. R Foundation for Sta- tistical Computing, ISBN 3-900051-07-0. http://www.Rproject.org.

Rasmussen, B., I.R. Fletcher, J.J. Brocks \& M.R. Kilburn. 2008. Reassessing the first appearance of eukaryotes and cyanobacteria. Nature, 455: 1101-1104.

Reynolds, C.S. \& A.E. Walsby. 1975. Water blooms. Biol. Rev., 50: 437-481.

Robarts, R.D. \& T. Zohary. 1987. Temperature effects on photosynthesis capacity, respiration, and growth rates of bloom-forming cyanobacteria. N.Z.J. Mar. Freshwat. Res., 21: 391-399.

Ryding, S.O. \& W. Rast. 1989. The control of eutrophication of lakes and reservoirs. Unesco and Parthenon Publishing Group: 314 pp.

Sala, O.E., F.S. Chapin, J.J.Armesto, E. Berlow, J. Bloomfield, R. Dirzo, E. Huber-Sanwald, L.F. Huenneke, R.B. Jackson, A. Kinzig, R. Leemans, D.M. Lodge, H.A. Mooney, M. Oesterheld, N. Leroy Poff, M.T. Sykes, B.H. Walker, M. Wallker \& D.H. Wall. 2000. Global Biodiversity Scenarios for the Year 2100. Science. Review: Biodiversity: $1770-1774$

Schopf, J.W. 2000. The fossil record: Tracing the roots of the cyanobacterial lineage. In: B.A. Whitton \& M. Potts (Eds), The ecology of cyanobacteria. Dordecht, the Netherlands: KluwerAcademic Publishers: 13-15.

Shannon, C.E. \& W. Weaver. 1949. The mathematical theory of communication. University of Illionois, Urbana: $118 \mathrm{pp}$.

Søndergaard, P.A. 1997. Factors affecting the timing of surface scums and epilimnetic blooms of blue-green algae ina a eutrophic lake. Hydrobiologia, 506: 135-145.

Straile, D. 2000. Meteorological forcing of plankton dynamics in a large and deep continental European lake. Oecologia, 122: 44-50.

Utermöl, H. 1958. Zur Vervollkommenung der quantitativen Phytoplankton Methodik. Mitt. Int. Ver. Limnol., 9: 1-38.

Wager, C. \& R. Adrian. 2009. Cyanobacteria dominance: Quantifiying the effects of climate change. Limnol. Oceangr., 54: 240-2468.

Winder, M. \& D.E. Schindler. 2004. Climatic effects on the phenology of lake processes. Global Change Biology, 10: 1844-1856. 